\title{
Static Analysis of Reddy-Bickford Composite and Sandwich Beams via Ritz Method
}

\author{
Armağan Fatih Karamanlı* \\ Istanbul Gelisim University, Department of Mechatronics, Faculty of Engineering and Architecture \\ Istanbul Gelişim University, 34215, Istanbul, Turkey 021247200 00, \\ afkaramanli@gelisim.edu.tr \\ *Corresponding author \\ Received: 16 June 2017 \\ Accepted: 23 December 2017 \\ DOI: $10.18466 /$ cbayarfbe.321889
}

\begin{abstract}
This paper is dedicated to present static behaviour of Reddy-Bickford laminated composite and sandwich beams subjected to various sets of boundary conditions which are simply supported (SS), clamped-simply supported (CS), clamped-clamped (CC) and clamped-free (CF) by using Ritz method. An analytical solution based on polynomial series including auixiliary functions which are used to satisfy the boundary conditions is developed to solve the studied problem. The polynomial shape functions for axial, transverse deflections and the rotation of the crosssection are presented. The validation and convergence studies are performed by solving symmetric and antisymmetric cross-ply composite beam problems with various boundary conditions and aspect ratios. The numerical results in terms of mid-span deflections, axial and shear stresses are obtained to make comparison with previous studies and to investigate the accuracy of the present study. The effects of fiber angle, lay-up and aspect ratio on displacements and stresses are studied. The static response of the various laminated composite sandwich structures which have symmetric lay-up based on the various boundary conditions, fiber angles and thickness ratios is also studied. It is found that the polynomial series with auxiliary functions can be used for the static analysis of the composite and sandwich beams via Ritz method.
\end{abstract}

Keywords: Composite; Sandwich Beam; Static Analysis; Ritz Method; Reddy-Bickford Beam Theory

\section{Introduction}

The use of composite beam structures has been increasing in several engineering applications due to their high stiffness, anisotropic material property and strength to weight ratio. To understand the mechanical behavior of these structures, researchers have been developed various beam theories in recent years, the review of these theories can be found in [1]. There are a number of beam theories which have presented the kinematics of deformation. Among them, the most commonly used is the Euler Bernoulli Beam Theory (EBT). Euler-Bernoulli beam theory (EBT) is widely used to solve the bending behaviour of the thin beams where the transverse shear deformation is neglected. If the beam is short or thick, the transverse shear deformation should be taken into account and refined shear deformation theories are needed.

The Timoshenko Beam Theory (TBT) and the Reddy-Bickford Beam Theory (RBT) are commonly used for the buckling, vibration and static analysis of thin and thick beam structures. In the TBT, the normality assumption of the EBT is relaxed and the cross sections do not need to normal to the mid-plane but still remain plane. The TBT requires the shear correction factor (SCF) to compensate the error due to the assumption of the constant transverse shear strain and shear stress through the beam thickness. The SCF depends on the geometric and material parameters of the beam but the loading and boundary conditions are also important to determine the SCF [2-3]. In the third order shear deformation theory which is named as the RBT, the transverse shear strain is quadratic trough the thickness of the beam and does not need to use a SCF. Many higher order beam theories (HBT) including quasi-3D ones (HBT) have been developed to study the bending behaviour of composite beams and only some of them [4-14] are referenced here. The static behavior of of composite and sandwich beams have been investigated by using analytical and numerical methods. Among them, the finite element methods are the most commonly used ones for the analysis of composite beams [15-28]. There are a few studies realted to the 
flexure analysis of laminated composite and sandwich beams by employing a meshless method [29-33]. The Navier solution is the simplest one which can be used only for the solution of the problems with SS boundary condition [34-36] as an analytical approach. In order to deal with arbitrary end conditions, many different methods have been developed. The most commonly used one is the Ritz method [38-41].

As it is seen from above literature survey, the studies related to static analysis of the laminated composite and sandwich beams by employing Ritz method are still limited. The main scope of this work is to investigate the static behaviour of the Reddy-Bickford laminated composite and sandwich beams by using Ritz method with polynomial shape functions. In the persent paper, the static analysis of the laminated composite and sandwich beams are presented by considering various fibre angles, lay-ups, aspect ratios and sets of boundary conditions. In section 2 , the theory and formulation are given. In Section 3, numerical results are given for the problems with four different boundary conditions which are simply supported (SS), clamped-simply supported (CS), clamped-clamped (CC) and clamped-free (CF).

\section{Theory and Formulation}

In Fig. 1, a laminated composite beam which is made of many plies of orthotropic materials in different orientations with respect to $\mathrm{x}$-axis is presented. It is assumed that a lamina has no gaps or empty spaces, behaves as a linear elastic material and is bounded perfectly to each other.

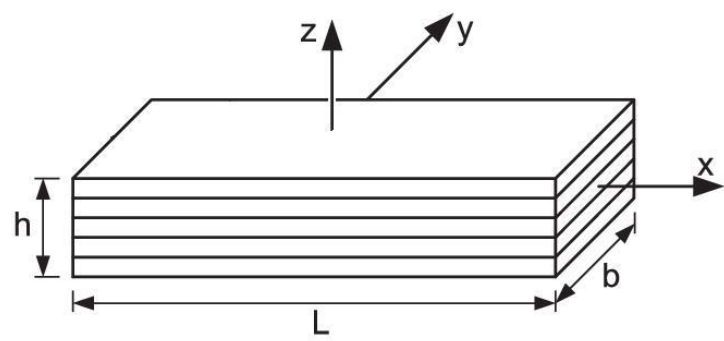

Figure 1 Geometry of a laminated composite beam.

Where $\mathrm{h}$ is the height of the beam, $\mathrm{b}$ is the width and $\mathrm{L}$ is the length. The stress-strain relationship of a $\mathrm{k}^{\text {th }}$ orthotropic lamina in the material coordinate axes is given by:

$\left\{\begin{array}{l}\sigma_{x x} \\ \sigma_{x Z}\end{array}\right\}^{k}=\left[\begin{array}{cc}Q_{11} & 0 \\ 0 & Q_{55}\end{array}\right]^{k}\left\{\begin{array}{l}\varepsilon_{x x} \\ \gamma_{x z}\end{array}\right\}$

where $\left(\sigma_{x x}, \sigma_{x z}\right)$ are the stresses and $\left(\varepsilon_{x x}, \gamma_{x z}\right)$ are the strains with respect to the laminate axes. $Q_{i j}$ 's are the transformed elastic constants or stiffness matrix with respect to laminate axis $\mathrm{x}$. The transformed elastic constant can be given by:
$Q_{11}=C_{11} \cos ^{4} \theta+2\left(C_{12}+2 C_{66}\right) \cos ^{2} \theta \sin ^{2}+C_{22} \sin ^{4} \theta$

$Q_{55}=C_{44} \sin ^{2} \theta+C_{55} \cos ^{2} \theta$

where

$$
\begin{gathered}
C_{11}=\frac{E_{1}}{1-v_{12} v_{21}} ; C_{12}=\frac{E_{1} v_{21}}{1-v_{12} v_{21}} ; C_{22}=\frac{E_{2}}{1-v_{12} v_{21}} ; \\
C_{66}=G_{12} ; C_{55}=G_{13} ; C_{44}=G_{23}
\end{gathered}
$$

$E_{1}, E_{2}, G_{12}, G_{13}, G_{23}, v_{12}$ and $v_{21}$ are the six independent engineering constants. To describe the RBT the following coordinate system is introduced. The $\mathrm{x}$-coordinate is taken along the axis of the beam and the z-coordinate is taken through the height (thickness) of the beam. In the general beam theory, all the loads and the displacements $(u, w, \varphi)$ along the coordinates $(\mathrm{x}, \mathrm{z})$ are only the functions of the $\mathrm{x}$ and $\mathrm{z}$ coordinates.

The following displacement field is given for the RBT,

$U(x, z)=u(x)+z \phi(x)-\alpha z^{3}\left(\phi(x)+\frac{d w(x)}{d x}\right)$
$W(x, z)=w(x)$

Here $u$ and $w$ are the axial and transverse displacements of any point on the neutral axis, $\phi$ is the rotation of the cross sections and $\alpha=4 /\left(3 h^{2}\right)$. By using the Eq. (2.3), the strain-displacement relations of the RBT are given by

$$
\begin{gathered}
\varepsilon_{x x}=\frac{d U}{d x}=\frac{d u}{d x}+z \frac{d \phi}{d x}-\alpha z^{3}\left(\frac{d \phi}{d x}+\frac{d^{2} w}{d x^{2}}\right) \\
\gamma_{x z}=\frac{d U}{d z}+\frac{d W}{d x}=\phi+\frac{d w}{d x}-\beta z^{2}\left(\phi+\frac{d w}{d x}\right)
\end{gathered}
$$

where $\beta=3 \alpha=4 /\left(h^{2}\right)$.

The strain energy of the beam including the energy associated with the shearing strain can be written as,

$U=\frac{1}{2} \int_{V}\left(\sigma_{x x} \varepsilon_{x x}+\sigma_{x z} \gamma_{x z}\right) d V$

where $V$ is the volume of the beam. By substituting Eqs. (2.1) and (2.4) into Eq. (2.5), the strain energy can be obtained as the form of: 


$$
\begin{aligned}
& U=\frac{1}{2} \int_{V}\left[Q _ { 1 1 } \left\{\left(\frac{d u}{d x}\right)^{2}+\left(z^{2}+\alpha^{2} z^{6}-2 \alpha z^{4}\right)\left(\frac{d \phi}{d x}\right)^{2}\right.\right. \\
& +\alpha^{2} z^{6}\left(\frac{d^{2} w}{d x^{2}}\right)^{2}+2\left(z-\alpha z^{3}\right) \frac{d u}{d x} \frac{d \phi}{d x}-2 \alpha z^{3} \frac{d u}{d x} \frac{d^{2} w}{d x^{2}} \\
& \left.+2\left(\alpha^{2} z^{6}-\alpha z^{4}\right) \frac{d \phi}{d x} \frac{d^{2} w}{d x^{2}}\right\} \\
& +Q_{55}\left\{\left(1+\beta^{2} z^{4}-2 \beta z^{2}\right) \phi^{2}+\left(1+\beta^{2} z^{4}\right.\right. \\
& \left.-2 \beta z^{2}\right)\left(\frac{d w}{d x}\right)^{2}+2\left(1+\beta^{2} z^{4}\right. \\
& \left.\left.\left.-2 \beta z^{2}\right) \phi \frac{d w}{d x}\right\}\right] d V
\end{aligned}
$$

The potential energy of the load $\mathrm{q}(\mathrm{x})$ is given by

$$
V=-\int_{-\frac{L}{2}}^{\frac{L}{2}} q w d x
$$

The stiffness coefficients can be introduced as follows: $(A, B, C, D, F, H)$

$$
\begin{aligned}
& =b \int_{-\frac{h}{2}}^{+\frac{h}{2}} Q_{11}\left(1, z, z^{2}, z^{3}, z^{4}, z^{6}\right) d z \\
& \left(A_{s}, D_{s}, F_{S}\right)=b \int_{-h / 2}^{+h / 2} Q_{55}\left(1, z^{2}, z^{4}\right) d z
\end{aligned}
$$

By using Eqs. (2.6) to (2.9), the total potential energy (П) can be written in the form of:

$$
\begin{aligned}
\Pi=U+V & \frac{1}{2} \int_{-L / 2}^{L / 2}\left[A\left(\frac{d u}{d x}\right)^{2}+\left(D+\alpha^{2} H-2 \alpha F\right)\left(\frac{d \phi}{d x}\right)^{2}\right. \\
& +\alpha^{2} H\left(\frac{d^{2} w}{d x^{2}}\right)^{2}+2(B-\alpha C) \frac{d u}{d x} \frac{d \phi}{d x} \\
& -2 \alpha C \frac{d u}{d x} \frac{d^{2} w}{d x^{2}} \\
& +2\left(\alpha^{2} H-\alpha F\right) \frac{d \phi}{d x} \frac{d^{2} w}{d x^{2}} \\
& +\left(A_{s}+\beta^{2} F_{s}-2 \beta D_{s}\right)\left\{\phi^{2}+\left(\frac{d w}{d x}\right)^{2}\right. \\
& \left.\left.+2 \phi \frac{d w}{d x}\right\}-2 q w\right] d x
\end{aligned}
$$

The mid-span deflections, axial and shear stresses are obtained by using the Ritz method. The displacement functions $u(\mathrm{x}), \mathrm{w}(\mathrm{x})$ and $\phi(x)$ are presented by the following polynomial series which are satisfy the kinematic boundary conditions given in Table 1,

$$
\begin{aligned}
& u(x)=\sum_{j=1}^{m} a_{j} \theta_{j}(x) \\
& \theta_{j}(x)=\left(x+\frac{L}{2}\right)^{p_{u}}\left(x-\frac{L}{2}\right)^{q_{u}} x^{j-1} \\
& w(x)=\sum_{j=1}^{m} b_{j} \varphi_{j}(x), \\
& \varphi_{j}(x)=\left(x+\frac{L}{2}\right)^{p_{w}}\left(x-\frac{L}{2}\right)^{q_{w}} x^{j-1} \\
& \phi(x)=\sum_{j=1}^{m} c_{j} \psi_{j}(x), \\
& \psi_{j}(x)=\left(x+\frac{L}{2}\right)^{p_{\phi}}\left(x-\frac{L}{2}\right)^{q_{\phi}} x^{j-1}
\end{aligned}
$$

where $a_{j}, b_{j}$ and $c_{j}$ are unknown values to be determined, $\theta_{j}(x), \varphi_{j}(x)$ and $\psi_{j}(x)$ are the shape functions which are proposed for the boundary conditions (BC) to be studied within this paper, $p_{\xi}$ and $q_{\xi}(\xi=u, w, \phi)$ are the boundary exponents of auxiliary functions related with the boundary conditions given in Table 2. It has to be mentioned that the shape functions which do not satisfy the boundary conditions may cause slow convergence rates and numerical instabilities.

One can substitute Eq. (11) into Eq. (10) and then use the principle of the minimum potential energy given by Eq. (2.12) to obtain the system of equations and determine the values of $a_{j}, b_{j}$ and $c_{j}$.

$$
\frac{\partial \Pi}{\partial a_{j}}=0, \quad \frac{\partial \Pi}{\partial b_{j}}=0, \quad \frac{\partial \Pi}{\partial c_{j}}=0, \quad j=1,2,3, \ldots, m
$$

Table 1. Kinematic boundary conditions used for the numerical computations.

\begin{tabular}{|c|c|c|}
\hline $\mathrm{BC}$ & $\mathrm{x}=-\mathrm{L} / 2$ & $\mathrm{x}=\mathrm{L} / 2$ \\
\hline $\mathrm{SS}$ & $\mathrm{u}=0, \mathrm{w}=0$ & $\mathrm{w}=0$ \\
\hline \multirow{2}{*}{$\mathrm{CS}$} & $\mathrm{u}=0, \mathrm{w}=0$, & $\mathrm{w}=0$ \\
& $\phi=0, \mathrm{w}^{\prime}=0$ & $\mathrm{u}=0, \mathrm{w}=0$, \\
$\mathrm{C} C \mathrm{C}$ & $\mathrm{u}=0, \mathrm{w}=0$, & $\phi=0, \mathrm{w}^{\prime}=0$ \\
\hline \multirow{2}{*}{$\mathrm{CF}$} & $\phi=0, \mathrm{w}^{\prime}=0$ & \\
& $\mathrm{u}=0, \mathrm{w}=0$, & \\
& $\phi=0, \mathrm{w}^{\prime}=0$ & \\
\hline
\end{tabular}

Table 2. Boundary exponents for various boundary conditions.

\begin{tabular}{|c|c|c|c|c|c|c|}
\hline \multirow{2}{*}{$\mathrm{BC}$} & \multicolumn{3}{|c|}{ Left end } & \multicolumn{3}{c|}{ Right end } \\
\cline { 2 - 7 } & $p_{u}$ & $p_{w}$ & $p_{\phi}$ & $q_{u}$ & $q_{w}$ & $q_{\phi}$ \\
\hline $\mathrm{SS}$ & 1 & 1 & 0 & 0 & 1 & 0 \\
\hline $\mathrm{CS}$ & 1 & 2 & 1 & 0 & 1 & 0 \\
\hline $\mathrm{CC}$ & 1 & 2 & 1 & 1 & 2 & 1 \\
\hline $\mathrm{CF}$ & 1 & 2 & 1 & 0 & 0 & 0 \\
\hline
\end{tabular}


Celal Bayar University Journal of Science

Volume 13, Issue 4, p 933-942

\section{Numerical Results}

This section is presented to understand the static behaviour of the composite beams based on the RBT formulations and the Ritz method. The numerical results obtained by employing different number of terms in the polynomial series expansions are used for convergence and verification studies. The results are presented in terms of displacements and stresses of composite beams considering various lay-ups, aspect ratios and boundary conditions.

Table 3. Material properties of composite and sandwich beams

\begin{tabular}{|c|l|}
\hline Structure & \multicolumn{1}{|c|}{ Material Properties } \\
\hline \multirow{4}{*}{ Type $A$} & $\mathrm{E}_{1} / \mathrm{E}_{2}=25 ; \mathrm{E}_{3}=\mathrm{E}_{2} ; \mathrm{G}_{12}=\mathrm{G}_{13}=$ \\
& $0.5 \mathrm{E}_{2} ; \mathrm{G}_{23}=0.2 \mathrm{E}_{2}$ \\
& $\mathrm{v}_{12}=\mathrm{v}_{13}=\mathrm{v}_{23}=0.25$ \\
\hline \multirow{5}{*}{ Type $\mathrm{B}$} & Face Layer: Type $\mathrm{A}$ \\
\cline { 2 - 2 } & $\begin{array}{l}\text { Core Layer: } \mathrm{E}_{1} / \mathrm{E}_{2}=1 ; \mathrm{E}_{3}=\mathrm{E}_{2} ; \mathrm{G}_{12}= \\
\mathrm{G}_{13}=1.5 \mathrm{E}_{2} ; \mathrm{G}_{23}=0.4 \mathrm{E}_{2} \\
\\
\mathrm{v}_{12}=\mathrm{v}_{13}=\mathrm{v}_{23}=0.25\left(\mathrm{E}_{2} \text { is same for }\right. \\
\text { faces and core layers })\end{array}$ \\
\hline
\end{tabular}

The results from previous studies $[5,8]$ in terms of dimensionless mid-span deflections, axial and shear stresses are used for comparison purposes by considering three different aspect ratios $(\mathrm{L} / \mathrm{h}) 5,10$ and 50 are considered. The material properties for the composite beams studied within this paper are given in Table 3. The following non-dimensional quantities are used for the representation of the results; Non-dimensional maximum transverse deflection of the beam:

$\bar{w}=\frac{100 E_{m} b h^{3}}{q_{0} L^{4}} w(0, z)$

Non-dimensional axial and shear stresses of the beam:

$\bar{\sigma}_{x}=\frac{b h^{2}}{q_{0} L^{2}} \sigma_{x}(0, z) ; \quad \bar{\sigma}_{x z}=\frac{b h}{q_{0} L} \sigma_{x z}\left(-\frac{L}{2}, z\right)$

\subsection{Verification, Comparison and Convergence Stud- ies}

Symmetric and anti-symmetric cross-ply composite beams subjected to uniformly distributed load with various boundary conditions (SS, CF, CC and $\mathrm{CS}$ ) and aspect ratios are investigated to verify the developed code with respect to the different series number $\mathrm{m}$. The present results agree well with those from previous studies $[5,8]$. It is clear that for the static analysis, the responses converge quickly for all types of boundary conditions when $\mathrm{m}$ is set to 8 as it is seen from Tables 4 and 5. It is seen that for the deflection analysis 10 terms in the polynomial expansion gives accurate results which are good agreement with the previous studies. However, for the stress analysis, using 10 terms in

\section{A.F. Karamanl1}

the polynomial expansion could not provide satisfactory results. So that for the further stress analysis $m$ is set to 8 . Moreover, a beam with CF boundary condition should be studied by employing 12 terms in the polynomial expansion to obtain accurate results in terms of mid-span deflections.

The approximation functions which are $\theta_{j}(x), \varphi_{j}(x)$ and $\psi_{j}(x)$ should be continuous as required in Eq.(2.10), linearly independent, complete and satisfy kinematic boundary conditions. If these functions are linearly independent and complete, the assumed approximation for the displacements converges to the exact solution with an increase in the number of term. Since the strains are computed based on an approximate displacement field, generally the strains and stresses are less accurate than the displacements. A mathematical proof can be found in [42-44].

\subsection{Bending Analysis of Laminated Composite and Sandwich Beams}

Various boundary conditions are considered to investigate the flexural behavior of the laminated composite and sandwich beams under uniformly distributed load. Different lay-ups, fiber angles and aspect ratios are employed to obtain numerical results in terms of the mid-span deflections, axial and shear stresses based on the RBT Theory.

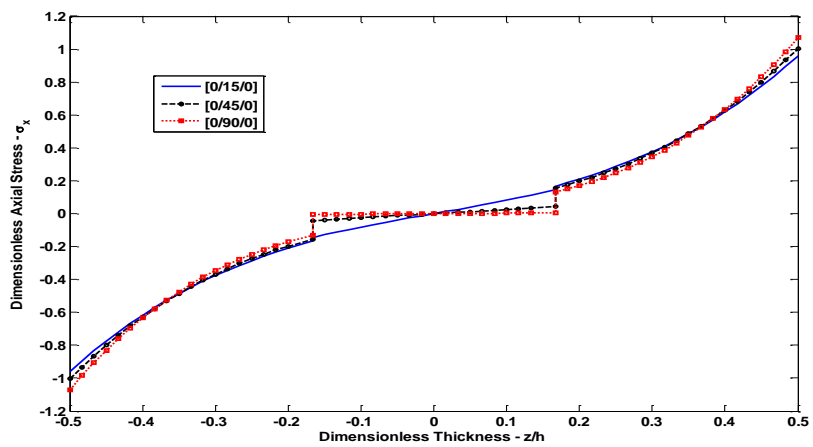

a. Symmetric lay-up

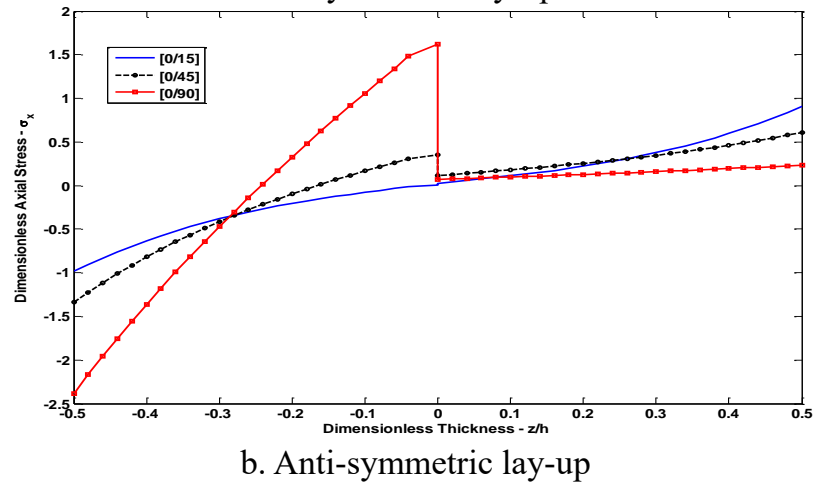

Figure 2 Axial stress distribution through the thickness of symmetric and anti-symmetric beams with $\mathrm{S}-\mathrm{S}$ boundary condition based on RBT, Type $\mathrm{A}, \mathrm{L} / \mathrm{h}=5$. 


\subsubsection{Laminated Composite Beams: Type A}

In this example the symmetric $\left[0^{\circ} / \theta / 0^{\circ}\right]$ and unsymmetric $\left[0^{\circ} / \theta\right]$ composite beams are studied. In Tables 6 and 7, variations of mid-span displacements, axial and shear stresses respect to the fiber angle $(\theta)$ are revealed. It is explicit that as the fiber angle increases, mid-span deflections and maximum axial and shear stress values increase for any type of boundary conditions and aspect ratios. The midspan deflection and axial stress decrease while the aspect ratio increases. One can easily notice that for all type of lay-ups, the shear stress increases when the aspect ratio increases. It is displayed in Figs. 2 and 3 that the fiber angle increases while the dimensionless maximum axial and shear stresses increase with respect to all type of boundary conditions and aspect ratios. It is clear that the discontinuities are visible for studied composite beam structures.

\subsubsection{Laminated Composite Sandwich Beams: Type B} This example is dedicated to investigate the static deformations of cross-ply sandwich beams (Type B) subjected to uniformly distributed load with the top and bottom face thickness $\left(h_{1}\right)$ and core thickness $\left(h_{2}\right)$. The dimensionless mid-span deflections and stresses are presented in Tables 8 and 9 for various thickness and aspect ratios by employing the Ritz method. It is observed that the dimensionless midspan deflections increase while the thickness ratio increases. In Fig. 4, the dimensionless axial and shear stress variations through thickness of the sandwich beams are displayed for various thickness ratios. It is noteable that, the maximum stresses increase as the thickness ratio changes from 3 to 8 . The maximum dimensionless axial and shear stresses are computed while the thickness value is set to 8 .

Table 4. Verification and convergence studies, dimensionless mid-span deflections for different number of terms.

\begin{tabular}{|c|c|c|c|c|c|c|c|}
\hline \multirow{2}{*}{ Theory } & \multirow{2}{*}{ Reference } & \multicolumn{3}{|c|}{ Symmetric $\left(0^{\circ} / 90^{\circ} / 0^{\circ}\right)$} & \multicolumn{3}{|c|}{ Anti-symmetric $\left(0^{\circ} / 90^{\circ}\right)$} \\
\hline & & $\mathrm{L} / \mathrm{h}=5$ & 10 & 50 & $\mathrm{~L} / \mathrm{h}=5$ & 10 & 50 \\
\hline \multicolumn{8}{|c|}{ a. $\quad$ Simply Supported Beams (S-S) } \\
\hline RBT & Khdeir and Reddy [5] & 2.412 & 1.096 & 0.665 & 4.777 & 3.688 & 3.336 \\
\hline \multirow{5}{*}{ RBT } & 2 terms & 2.2631 & 0.9657 & 0.5352 & 4.1051 & 3.0235 & 2.6720 \\
\hline & 4 terms & 2.4201 & 1.0972 & 0.6645 & 4.7810 & 3.6886 & 3.3363 \\
\hline & 6 terms & 2.4103 & 1.0959 & 0.6645 & 4.7750 & 3.6881 & 3.3363 \\
\hline & 8 terms & 2.4127 & 1.0965 & 0.6645 & 4.7773 & 3.6884 & 3.3363 \\
\hline & 10 terms & 2.4123 & 1.0963 & 0.6645 & 4.7767 & 3.6882 & 3.3363 \\
\hline \multicolumn{8}{|c|}{ b. Cantilever Beams (C-F) } \\
\hline RBT & Khdeir and Reddy [5] & 6.824 & 3.455 & 2.251 & 15.279 & 12.343 & 11.337 \\
\hline \multirow{6}{*}{ RBT } & 2 terms & 5.2901 & 2.9104 & 2.1027 & 13.3349 & 11.3189 & 10.6569 \\
\hline & 4 terms & 6.7854 & 3.4122 & 2.2474 & 15.1831 & 12.2916 & 11.3337 \\
\hline & 6 terms & 6.7924 & 3.4297 & 2.2487 & 15.2213 & 12.3116 & 11.3347 \\
\hline & 8 terms & 6.8267 & 3.4558 & 2.2505 & 15.2827 & 12.3406 & 11.3362 \\
\hline & 10 terms & 6.8235 & 3.4538 & 2.2506 & 15.2769 & 12.3399 & 11.3364 \\
\hline & 12 terms & 6.8240 & 3.4554 & 2.2511 & 15.2791 & 12.3435 & 11.3368 \\
\hline \multicolumn{8}{|c|}{ c. $\quad$ Cantilever Beams (C-C) } \\
\hline RBT & Khdeir and Reddy [5] & 1.537 & 0.532 & 0.147 & 1.922 & 1.005 & 0.679 \\
\hline \multirow{5}{*}{ RBT } & 2 terms & 1.5312 & 0.5129 & 0.1451 & 1.8838 & 0.9816 & 0.6772 \\
\hline & 4 terms & 1.5087 & 0.5106 & 0.1451 & 1.8724 & 0.9807 & 0.6772 \\
\hline & 6 terms & 1.5396 & 0.5330 & 0.1466 & 1.9262 & 1.0050 & 0.6784 \\
\hline & 8 terms & 1.5366 & 0.5303 & 0.1465 & 1.9198 & 1.0026 & 0.6783 \\
\hline & 10 terms & 1.5370 & 0.5318 & 0.1469 & 1.9219 & 1.0058 & 0.6787 \\
\hline \multicolumn{8}{|c|}{ d. $\quad$ Cantilever Beams $(\mathrm{C}-\mathrm{S})$} \\
\hline RBT & Khdeir and Reddy [5] & 1.952 & 0.740 & 0.280 & 2.863 & 1.740 & 1.346 \\
\hline \multirow{5}{*}{ RBT } & 2 terms & 1.8008 & 0.6962 & 0.1570 & 2.4912 & 1.2426 & 0.6903 \\
\hline & 4 terms & 1.9409 & 0.7178 & 0.2773 & 2.8127 & 1.7081 & 1.3437 \\
\hline & 6 terms & 1.9405 & 0.7335 & 0.2794 & 2.8446 & 1.7337 & 1.3455 \\
\hline & 8 terms & 1.9530 & 0.7401 & 0.2792 & 2.8643 & 1.7381 & 1.3453 \\
\hline & 10 terms & 1.9516 & 0.7396 & 0.2796 & 2.8619 & 1.7392 & 1.3458 \\
\hline
\end{tabular}


Celal Bayar University Journal of Science

Volume 13, Issue 4, p 933-942

A.F. Karamanl 1

Table 5. Verification and convergence studies, dimensionless axial $\bar{\sigma}_{x}\left(0, \frac{h}{2}\right)$ and shear $\bar{\sigma}_{x z}\left(-\frac{L}{2}, 0\right)$ stresses of S-S beams for different number of terms

\begin{tabular}{|c|c|c|c|c|c|c|c|}
\hline \multirow{2}{*}{ Theory } & \multirow{2}{*}{ Reference } & \multicolumn{3}{|c|}{ Symmetric $\left(0^{\circ} / 90^{\circ} / 0^{\circ}\right)$} & \multicolumn{3}{|c|}{ Anti-symmetric $\left(0^{\circ} / 90^{\circ}\right)$} \\
\hline & & $\mathrm{L} / \mathrm{h}=5$ & 10 & 50 & $\mathrm{~L} / \mathrm{h}=5$ & 10 & 50 \\
\hline \multicolumn{8}{|c|}{ a. $\quad$ Axial Stress $\left(\bar{\sigma}_{x}\right)$} \\
\hline RBT & Zenkour [8] & 1.0669 & 0.8500 & 0.7805 & 0.2362 & 0.2343 & 0.2336 \\
\hline \multirow{4}{*}{ RBT } & 2 terms & 0.7981 & 0.5903 & 0.5213 & 0.1582 & 0.1564 & 0.1558 \\
\hline & 4 terms & 1.0819 & 0.8516 & 0.7806 & 0.2362 & 0.2342 & 0.2336 \\
\hline & 6 terms & 1.0604 & 0.8486 & 0.7805 & 0.2361 & 0.2342 & 0.2336 \\
\hline & 8 terms & 1.0697 & 0.8512 & 0.7806 & 0.2362 & 0.2343 & 0.2336 \\
\hline \multicolumn{8}{|c|}{ b. $\quad$ Shear Stress $\left(\bar{\sigma}_{x Z}\right)$} \\
\hline RBT & Zenkour [8] & 0.4057 & 0.4311 & 0.4514 & 0.9211 & 0.9572 & 0.9860 \\
\hline \multirow{4}{*}{ RBT } & 2 terms & 0.4401 & 0.4523 & 0.4563 & 0.9770 & 0.9875 & 0.9922 \\
\hline & 4 terms & 0.4158 & 0.4436 & 0.4559 & 0.9479 & 0.9799 & 0.9919 \\
\hline & 6 terms & 0.4067 & 0.4356 & 0.4553 & 0.9272 & 0.9693 & 0.9913 \\
\hline & 8 terms & 0.4057 & 0.4320 & 0.4545 & 0.9213 & 0.9614 & 0.9906 \\
\hline
\end{tabular}

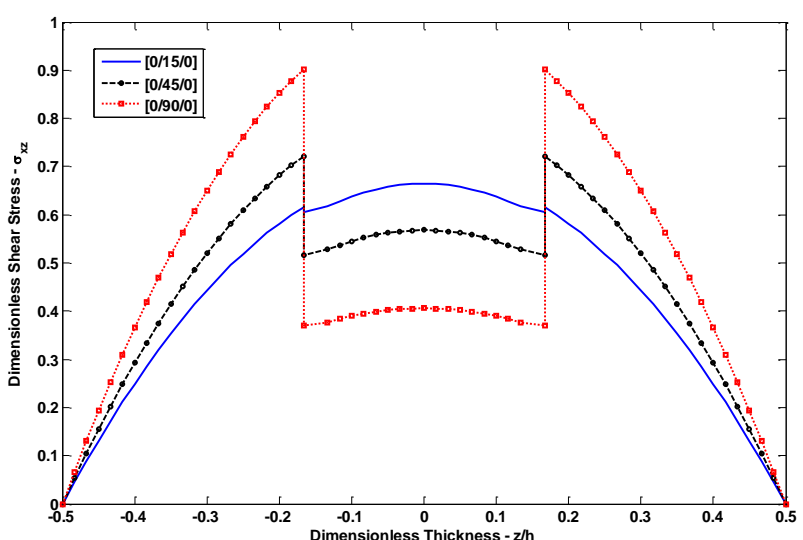

a. Symmetric lay-up

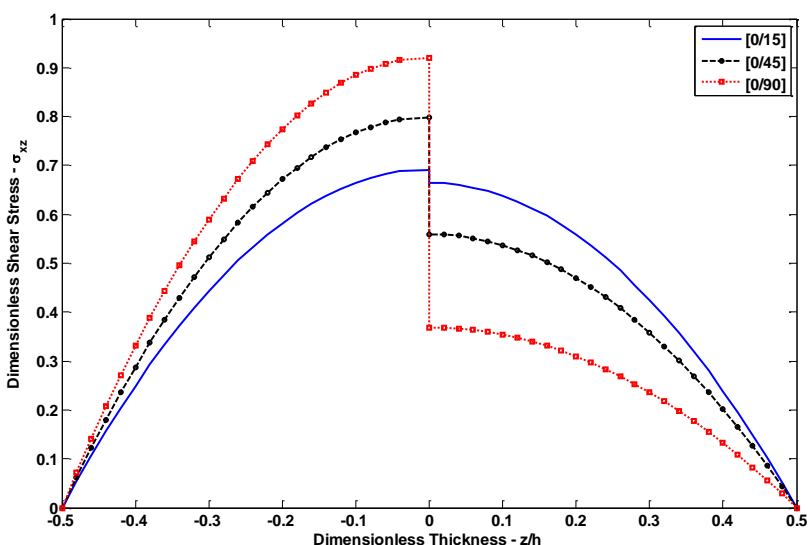

b. Asymmetric lay-up

Figure 3 Shear stress distribution through the thickness of symmetric and anti-symmetric beams with S-S boundary condition based on RBT, Type A, L/h=5.

Table 6. Dimensionless mid-span deflections of $\left[0^{\circ} / \theta / 0^{\circ}\right]$ and $\left[0^{\circ} / \theta\right]$ beams for various boundary conditions under a uniformly distributed load, Type A.

\begin{tabular}{|c|c|c|c|c|c|c|c|c|c|}
\hline \multicolumn{10}{|c|}{ 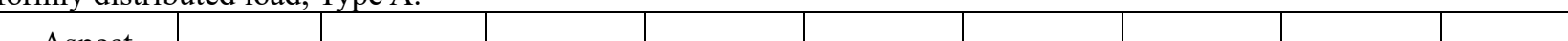 } \\
\hline $\begin{array}{c}\text { Aspect } \\
\text { Ratio }\end{array}$ & Theory & Lay-ups & $0^{\circ}$ & $15^{\circ}$ & $30^{\circ}$ & $45^{\circ}$ & $60^{\circ}$ & $75^{\circ}$ & $90^{\circ}$ \\
\hline \multicolumn{10}{|c|}{ a. $\quad$ Simply supported beams (SS) } \\
\hline \multirow{2}{*}{5} & \multirow{6}{*}{ RBT } & {$\left[0^{\circ} / \theta\right]$} & 1.8008 & 1.8693 & 2.1007 & 2.6212 & 3.6432 & 4.6080 & 4.7767 \\
\hline & & {$\left[0^{\circ} / \theta / 0^{\circ}\right]$} & 1.8008 & 1.8292 & 1.9133 & 2.0467 & 2.2091 & 2.3532 & 2.4127 \\
\hline \multirow{2}{*}{10} & & {$\left[0^{\circ} / \theta\right]$} & 0.9221 & 0.9711 & 1.1518 & 1.6068 & 2.5903 & 3.5400 & 3.6882 \\
\hline & & {$\left[0^{\circ} / \theta / 0^{\circ}\right]$} & 0.9221 & 0.9315 & 0.9581 & 0.9976 & 1.0426 & 1.0810 & 1.0965 \\
\hline \multirow{2}{*}{50} & & {$\left[0^{\circ} / \theta\right]$} & 0.6354 & 0.6787 & 0.8433 & 1.2777 & 2.2495 & 3.1947 & 3.3363 \\
\hline & & {$\left[0^{\circ} / \theta / 0^{\circ}\right]$} & 0.6354 & 0.6386 & 0.6463 & 0.6547 & 0.6608 & 0.6637 & 0.6645 \\
\hline \multicolumn{10}{|c|}{ b. Clamped simply supported beams (CS) } \\
\hline \multirow{2}{*}{5} & \multirow{6}{*}{ RBT } & {$\left[0^{\circ} / \theta\right]$} & 1.4107 & 1.4573 & 1.6059 & 1.8919 & 2.3616 & 2.7762 & 2.8619 \\
\hline & & {$\left[0^{\circ} / \theta / 0^{\circ}\right]$} & 1.4107 & 1.4362 & 1.5115 & 1.6308 & 1.7745 & 1.9002 & 1.9516 \\
\hline \multirow{2}{*}{10} & & {$\left[0^{\circ} / \theta\right]$} & 0.5737 & 0.5982 & 0.6843 & 0.8845 & 1.2900 & 1.6749 & 1.7392 \\
\hline & & {$\left[0^{\circ} / \theta / 0^{\circ}\right]$} & 0.5737 & 0.5818 & 0.6053 & 0.6420 & 0.6858 & 0.7240 & 0.7396 \\
\hline \multirow[b]{2}{*}{50} & & {$\left[0^{\circ} / \theta\right]$} & 0.2633 & 0.2808 & 0.3472 & 0.5216 & 0.9107 & 1.2890 & 1.3458 \\
\hline & & {$\left[0^{\circ} / \theta / 0^{\circ}\right]$} & 0.2633 & 0.2648 & 0.2685 & 0.2729 & 0.2765 & 0.2788 & 0.2796 \\
\hline
\end{tabular}


Celal Bayar University Journal of Science

Volume 13, Issue 4, p 933-942

A.F. Karamanlı

\begin{tabular}{|c|c|c|c|c|c|c|c|c|c|}
\hline \multicolumn{10}{|c|}{ c. Cantilever beams (CF) } \\
\hline \multirow{2}{*}{5} & \multirow{6}{*}{ RBT } & {$[0 \%$} & 5.2507 & 5.4707 & 6.2323 & 7.9694 & 11.4390 & 14.7241 & 15.2791 \\
\hline & & {$\left[0^{\circ} / \theta / 0^{\circ}\right]$} & 5.2507 & 5.3276 & 5.5525 & 5.9023 & 6.3174 & 6.6773 & 6.8240 \\
\hline \multirow{2}{*}{10} & & {$\left[0^{\circ} / \theta\right]$} & 2.9613 & 3.1259 & 3.7338 & 5.2728 & 8.6143 & 11.8432 & 12.3435 \\
\hline & & {$\left[0^{\circ} / \theta / 0^{\circ}\right]$} & 2.9613 & 2.9892 & 3.0675 & 3.1815 & 3.3081 & 3.4133 & 3.4554 \\
\hline \multirow{2}{*}{5(} & & {$\left[0^{\circ} / \theta\right]$} & 2.1551 & 2.3021 & 2.8612 & 4.3379 & 7.6418 & 10.8554 & 11.3368 \\
\hline & & {$\left[0^{\circ} / \theta / 0^{\circ}\right]$} & 2.1551 & 2.1655 & 2.1913 & 2.2196 & 2.2396 & 2.2488 & 2.2511 \\
\hline \multicolumn{10}{|c|}{ d. Clamped clamped beams (CC) } \\
\hline \multirow[b]{2}{*}{5} & \multirow{6}{*}{ RBT } & {$[0 \%$} & 1.0902 & 1.1236 & 1.2250 & 1.4007 & 1.6544 & 1.8703 & 1.9219 \\
\hline & & {$\left[0^{\circ} / \theta / 0^{\circ}\right]$} & 1.0902 & 1.1113 & 1.1739 & 1.2729 & 1.3918 & 1.4950 & 1.5370 \\
\hline \multirow{2}{*}{10} & & {$[0 \% / \theta$} & 0.3956 & 0.4103 & 0.4601 & 0.5687 & 0.7764 & 0.9711 & 1.0058 \\
\hline & & {$\left[0^{\circ} / \theta / 0^{\circ}\right]$} & 0.3956 & 0.4020 & 0.4209 & 0.4508 & 0.4870 & 0.5188 & 0.5318 \\
\hline \multirow{2}{*}{5} & & {$\left[0^{\circ} / \theta\right]$} & 0.1364 & 0.1452 & 0.1787 & 0.2662 & 0.4610 & 0.6502 & 0.6787 \\
\hline & & {$\left[0^{\circ} / \theta / 0^{\circ}\right]$} & 0.1364 & 0.1372 & 0.1394 & 0.1421 & 0.1446 & 0.1463 & 0.1469 \\
\hline
\end{tabular}

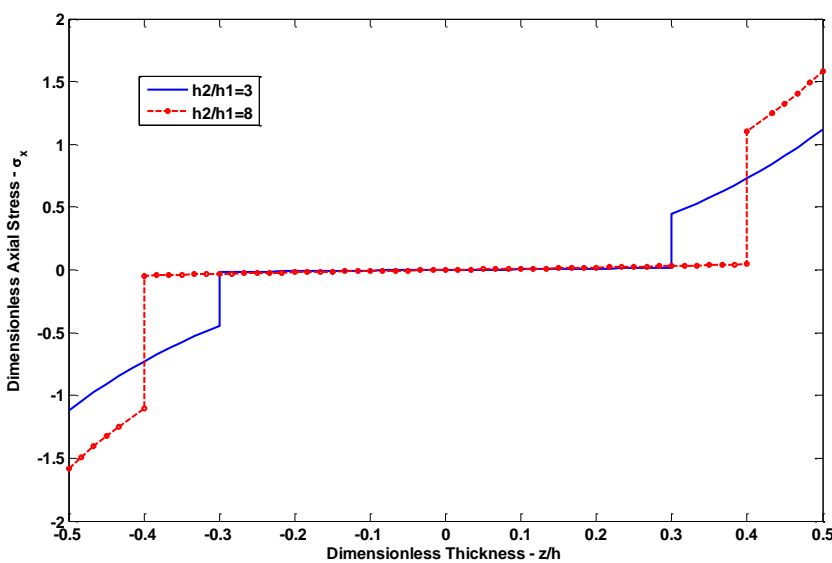

a. Axial Stress

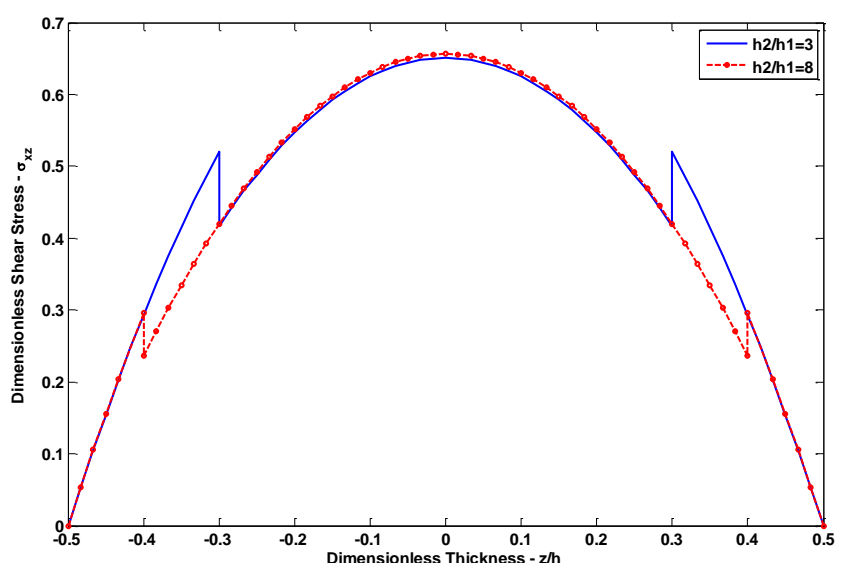

b. Shear Stress

Figure 4 Axial and shear stress distribution through the thickness of symmetric sandwich beams with S-S boundary condition based on RBT, Type $\mathrm{B}, \mathrm{L} / \mathrm{h}=5$.

Table 7. Dimensionless axial $\bar{\sigma}_{x}\left(0, \frac{h}{2}\right)$ and shear $\bar{\sigma}_{x z}\left(-\frac{L}{2}, 0\right)$ stresses of $\left[0^{\circ} / \theta / 0^{\circ}\right]$ and $\left[0^{\circ} / \theta\right]$ S-S beams under a uniformly distributed load, Type A.

\begin{tabular}{|c|c|c|c|c|c|c|c|c|c|}
\hline $\begin{array}{c}\text { Aspect } \\
\text { Ratio }\end{array}$ & Theory & Lay-ups & $0^{\circ}$ & $15^{\circ}$ & $30^{\circ}$ & $45^{\circ}$ & $60^{\circ}$ & $75^{\circ}$ & $90^{\circ}$ \\
\hline \multicolumn{10}{|c|}{ a. $\quad$ Axial stress $\left(\bar{\sigma}_{x}\right)$} \\
\hline \multirow{2}{*}{5} & \multirow{6}{*}{ RBT } & {$\left[0^{\circ} / \theta\right]$} & 0.9523 & 0.9161 & 0.8045 & 0.6489 & 0.4542 & 0.2787 & 0.2362 \\
\hline & & {$\left[0^{\circ} / \theta / 0^{\circ}\right]$} & 0.9523 & 0.9591 & 0.9779 & 1.0049 & 1.0347 & 1.0596 & 1.0697 \\
\hline \multirow{2}{*}{10} & & {$[0 \% / \theta]$} & 0.8009 & 0.7802 & 0.7109 & 0.6043 & 0.4421 & 0.2760 & 0.2343 \\
\hline & & {$\left[0^{\circ} / \theta / 0^{\circ}\right]$} & 0.8009 & 0.8051 & 0.8161 & 0.8294 & 0.8409 & 0.8485 & 0.8512 \\
\hline \multirow{2}{*}{50} & & {$[0 \% / \theta]$} & 0.7520 & 0.7364 & 0.6807 & 0.5900 & 0.4382 & 0.2751 & 0.2336 \\
\hline & & {$\left[0^{\circ} / \theta / 0^{\circ}\right]$} & 0.7520 & 0.7555 & 0.7639 & 0.7727 & 0.7783 & 0.7803 & 0.7806 \\
\hline \multicolumn{10}{|c|}{ b. $\quad$ Shear stress $\left(\bar{\sigma}_{x z}\right)$} \\
\hline \multirow{2}{*}{5} & \multirow{6}{*}{ RBT } & {$\left[0^{\circ} / \theta\right]$} & 0.6769 & 0.6923 & 0.7364 & 0.7993 & 0.8581 & 0.8999 & 0.9213 \\
\hline & & {$\left[0^{\circ} / \theta / 0^{\circ}\right]$} & 0.6769 & 0.6644 & 0.6272 & 0.5680 & 0.4958 & 0.4320 & 0.4057 \\
\hline \multirow{2}{*}{10} & & {$\left[0^{\circ} / \theta\right]$} & 0.7156 & 0.7311 & 0.7754 & 0.8386 & 0.8972 & 0.9390 & 0.9614 \\
\hline & & {$\left[0^{\circ} / \theta / 0^{\circ}\right]$} & 0.7156 & 0.7024 & 0.6634 & 0.6015 & 0.5262 & 0.4595 & 0.4320 \\
\hline \multirow{2}{*}{50} & & {$\left[0^{\circ} / \theta\right]$} & 0.7475 & 0.7629 & 0.8067 & 0.8691 & 0.9264 & 0.9674 & 0.9906 \\
\hline & & {$\left[0^{\circ} / \theta / 0^{\circ}\right]$} & 0.7475 & 0.7339 & 0.6935 & 0.6296 & 0.5519 & 0.4830 & 0.4545 \\
\hline
\end{tabular}


Table 8. Dimensionless mid-span deflections of $\left[0^{\circ} / 90^{\circ} / 0^{\circ}\right]$ beams for various boundary conditions under a uniformly distributed load, Type B.

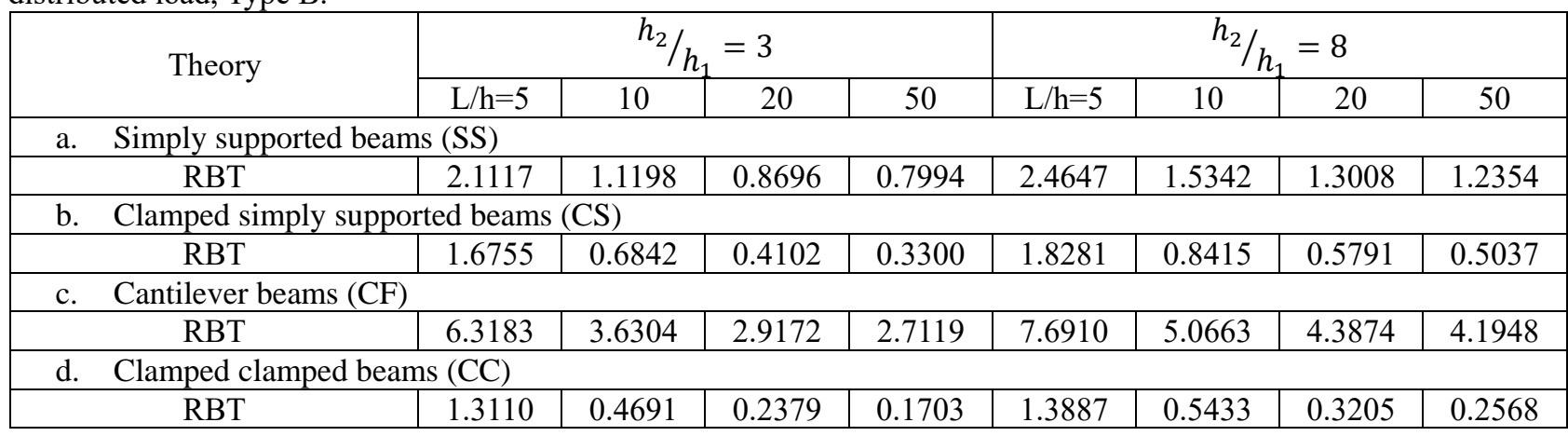

Table 9. Dimensionless axial $\bar{\sigma}_{x}\left(0, \frac{h}{2}\right)$ and shear $\bar{\sigma}_{x Z}\left(-\frac{L}{2}, 0\right)$ stresses of $\left[0^{\circ} / 90^{\circ} / 0^{\circ}\right]$ S-S beams under a uniformly distributed load, Type B.

\begin{tabular}{|c|c|c|c|c|c|c|c|c|}
\hline \multirow{2}{*}{ Theory } & \multicolumn{4}{|c|}{$h_{2} / h_{1}=3$} & \multicolumn{4}{|c|}{$h_{2} / h_{1}=8$} \\
\hline & $\mathrm{L} / \mathrm{h}=5$ & 10 & 20 & 50 & $\mathrm{~L} / \mathrm{h}=5$ & 10 & 20 & 50 \\
\hline \multicolumn{9}{|l|}{$\begin{array}{ll}\text { a. } & \text { Axial stress }\left(\bar{\sigma}_{x}\right)\end{array}$} \\
\hline RBT & 1.1229 & 0.9898 & 0.9565 & 0.9473 & 1.5823 & 1.4988 & 1.4781 & 1.4723 \\
\hline b. $\quad$ Shear stress $\left(\bar{\sigma}_{x z}\right)$ & & & & & & & & \\
\hline RBT & 0.6509 & 0.6781 & 0.6918 & 0.6973 & 0.6566 & 0.6732 & 0.6796 & 0.6818 \\
\hline
\end{tabular}

\section{Conclusion}

Based on the RBT formulation and the Ritz method, the static behavior of the laminated composite and sandwich beams is investigated by using the polynomial series expansions with auxiliary functions. Various composite and sandwich beam configurations are considered based on different aspect ratios, lay-ups, fiber angles, thickness ratios and boundary conditions. The numerical calculations in terms of mid-span deflections, axial and shear stresses are compared with the results which are obtained by other authors to validate the present model. It is found that computed results agree well with previous ones.

The selection of the number of terms in the polynomial expansion depend not only the formulation used in the numerical calculations but also depends on the boundary condition to be employed. For the deflection analysis, employed number of terms can be different according to the boundary conditions of the problem. It is clear that to obtain satisfactory results with a CF beam, higher number of terms should be employed in the polynomial expansion. Moreover, to obtain accurate results in terms of stresses, it is important to investigate optimum number of terms. Higher number of terms in the polynomial expansion may not produce satisfactory results regarding to the lower ones. It is also found that using the Ritz method with polynomial shape functions including auxiliary ones is simple to implement, efficient and provides quick convergence rates and expected results for the static analysis of laminated composite and sandwich beams.

\section{References}

1. Nguyen, TK, Nguyen, ND, Vo, TP, Thai HT, Trigonometric-series solution for analysis of laminated composite beams, Composite Structures, 2017,160, 142-151.

2. Timoshenko, SP, Goodier, JC, Theory of Elasticity, New York, NY, USA: McGraw-Hill Co. Inc., 1970.

3. Wang, CM, Reddy, JN, Lee, KH, Shear Deformable Beams and Plates Relations with Classical Solutions. Oxford: Elsevier Science Ltd., 2000 .

4. Kant, T, Manjunath, BS, Refined theories for composite and sandwich beams with C0 finite elements, Composite Structures, 1989, 33(3), 755-764.

5. Khdeir, AA, Reddy, JN, An exact solution for the bending of thin and thick cross-ply laminated beams, Composite Structures 1997, 37(2), 195-203.

6. Soldatos, KP, Watson, P, A general theory for the accurate stress analysis of homogeneous and laminated composite beams, International Journal of Solids and Structures, 1997, 34(22), 2857-2885.

7. Shi G, Lam, KY, Tay, TE, On efficient finite element modeling of composite beams and plates using higher-order theories and an accurate composite beam element, Compos Struct, 1998, 41(2),159-165.

8. Zenkour, AM, Transverse shear and normal deformation theory for bending analysis of laminated and sandwich elastic beams, Mechanics of Composite Materials \& Structures, 1999, 6(3), 267-283. 
Celal Bayar University Journal of Science

Volume 13, Issue 4, p 933-942

9. Karama, M, Afaq, KS, Mistou, S, Mechanical behaviour of laminated composite beam by the new multi-layered laminated composite structures model with transverse shear stress continuity, International Journal of Solids and Structures, 2003, 40(6),1525-1546.

10. Murthy, MVVS, Mahapatra, DR, Badarinarayana, K, Gopalakrishnan, S, A refined higher order finite element for asymmetric composite beams, Composite Structures, 2005, 67(1), 27-35.

11. Vidal, $\mathrm{P}$, Polit, $\mathrm{O}, \mathrm{A}$ family of sinus finite elements for the analysis of rectangular laminated beams, Composite Structures, 2008, 84(1),5672 .

12. Aguiar, RM, Moleiro, F, Soares CMM, Assessment of mixed and displacement-based models for static analysis of composite beams of different cross-sections, Composite Structures, 2012, 94 (2),601-616.

13. Nallim, LG, Oller, S, Onate, E, Flores, FG, A hierarchical finite element for composite laminated beams using a refined zigzag theory, Composite Structures, 2017, 163,168-184.

14. Vo, TP, Thai, HT, Nguyen, TK, Lanc, D, Karamanli, A, Flexural analysis of laminated composite and sandwich beams using a four-unknown shear and normal deformation theory, Composite Structures, 2017, 176,388-397.

15. Yuan, FG, Miller, RE, A higher order finite element for laminated beams, Composite Structures, 1990, 14(2), 125-150.

16. $\mathrm{Yu}, \mathrm{H}, \mathrm{A}$ higher-order finite element for analysis of composite laminated structures, Composite Structures, 1994, 28(4), 375-383.

17. Chandrashekhara, K, Bangera, K, Free vibration of composite beams using a refined shear flexible beam element, Composite Structures, 1992, 43(4), 719-727.

18. Marur, $S$, Kant, $T$, Free vibration analysis of fiber reinforced composite beams using higher order theories and finite element modelling, Journal of Sound and Vibration, 1996, 194(3), 337-351.

19. Karama, M, Harb, BA, Mistou, S, Caperaa, S, Bending, buckling and free vibration of laminated composite with a transverse shear stress continuity model, Composites Part B: Engineering, 1998, 29(3), 223234 .

20. Shi G, Lam K, Tay T, On efficient finite element modeling of composite beams and plates using higher-order theories and an accurate composite beam element, Composite Structures, 1998, 41(2), 159165 .

21. Shi, G, Lam, K, Finite element vibration analysis of composite beams based on higher-order beam theory, Journal of Sound and Vibration, 1999, 219(4),707-721.

22. Murthy, M, Mahapatra, DR, Badarinarayana K, Gopalakrishnan S, A refined higher order finite element for asymmetric composite beams, Composite Structures, 2005, 67(1), 27-35.

23. Subramanian, $P$, Dynamic analysis of laminated composite beams using higher order theories and finite elements, Composite Structures, 2006, 73 (3),342-353.

24. Vidal, $\mathrm{P}$, Polit, O, A family of sinus finite elements for the analysis of

\section{A.F. Karamanl}

rectangular laminated beams, Composite Structures, 2008, 84(1), 5672 .

25. Vo, TP, Thai, H-T, Static behavior of composite beams using various refined shear deformation theories, Composite Structures, 2012, 94(8), 2513-2522.

26. Vo, TP, Thai, H-T, Vibration and buckling of composite beams using refined shear deformation theory, International Journal of Mechanical Sciences, 2012, 62(1), 67-76.

27. Mantari, J, Canales, F, Finite element formulation of laminated beams with capability to model the thickness expansion, Composites Part B: Engineering, 2016, 101, 107-115.

28. Li, J, Wu, Z, Kong, X, Li, X, Wu, W, Comparison of various shear deformation theories for free vibration of laminated composite beams with general lay-ups, Composite Structures, 2014, 108, 767-778.

29. Ferreira, AJM, Roque, CMC, Martins, PALS, Radial basis functions and higher order shear deformation theories in the analysis of laminated composite beams and plates, Composite Structures, 2004, 66, 287-293.

30. Ferreira, AJM, Thick composite beam analysis using a global meshless approximation based on radial basis functions, Mechanics of Advanced Materials and Structures, 2003, 10, 271-284.

31. Roque, CMC, Fidalgo, DS, Ferreira, AJM, Reddy, JN, A study of a microstructure dependent composite laminated Timoshenko beam using a modified couple stress theory and a meshless method, Composite Structures, 2013, 96, 532-537.

32. Liew, KM, Lim, HK, Tan, MJ, He, XQ, Analysis of laminated composite beams and plates with piezoelectric patches using the elementfree Galerkin method, Computational Mechanics, 2002, 29, 486-497.

33. Karamanli, A, Flexure Analysis of Laminated Composite and Sandwich Beams Using Timoshenko Beam Theory, (Accepted for publication),

34. [34] Matsunaga $H$, Vibration and buckling of multilayered composite beams according to higher order deformation theories, Journal of Sound and Vibration, 2001, 246 (1), 47-62,

35. Mantari, J, Canales, $\mathrm{F}, \mathrm{A}$ unified quasi-3D HSDT for the bending analysis of laminated beams, Aerospace Science and Technology, 2016 , $54,267-275$.

36. Kant, T, Marur, S, Rao, G, Analytical solution to the dynamic analysis of laminated beams using higher order refined theory, Composite Structures, 1997,40 (1),1-9,

37. Aydogdu, M, Vibration analysis of cross-ply laminated beams with general boundary conditions by Ritz method, International Journal of Mechanical Sciences, 2005, 47(11), 1740-1755.

38. Aydogdu, M, Buckling analysis of cross-ply laminated beams with general boundary conditions by ritz method, Composite Science and Technology, 2006, 66(10), 1248-1255.

39. Aydogdu, M, Free vibration analysis of angle-ply laminated beams with general boundary conditions, Journal of Reinforced Plastics and Composites, 2006, 25(15), 1571-1583. 
Celal Bayar University Journal of Science

Volume 13, Issue 4, p 933-942

40. Mantari, J, Canales, F, Free vibration and buckling of laminated beams via hybrid Ritz solution for various penalized boundary conditions, Composite Structures, 2016, 152, 306-315.

41. Karamanli, A, Bending analysis of composite and sandwich beams using Ritz method, (Accepted for publication).

42. Rehfield, LW, Valisetty, RR, A Comprehensive Theory for Planar

\section{A.F. Karamanl1}

Bending of Composite Laminates, Computures and Structures, 1983, $15,441-447$.

43. Mau, ST, A Refined Laminate Plate Theory, Journal of Applied Mechanics, 1973, 40, 606-607.

44. Walts, TL, Vinson, JR, Interlaminar Stress in Laminated Cylindirical Shells of Composite Materials, AIAA Journal, 1976, 14, 1213-1218. 